\title{
El Segundo Plano de la Democracia y de la Sociedad Abierta, en el primer cuarto del Siglo XXI
}

\section{The Second Plane of Democracy and the Open Society, in the first quarter of the 21st Century}

Received: November 16, 2020

\section{Resumen}

El Siglo XXI nos presenta una nueva forma en que el mundo se comenzará a regular, luego del violento ordenamiento Unipolar que asoló a la humanidad, particularmente en la década de los noventa del siglo pasado y en los primeros ocho años de nuestra actual centuria. Estados Unidos, dominó el mundo en los últimos 40 años y hoy, se comienzan a observar los primeros síntomas de su declive como imperio. El giro geopolítico, debiera traer una oportunidad para la democracia y la sociedad abierta, de forma que se puedan plasmar de mejor manera en las diversas poblaciones del mundo. No obstante, la democracia deberá resistir un periodo tormentoso, que marca el fin de una era, en una situación de mucho desprestigio que sufre como régimen político y además debe, al mismo tiempo, dejar de ser un conjunto de reglas para comenzar el gobierno sobre el mercado. Nada fácil. El objetivo del artículo, junto con entrever el declive de EEUU como potencia hegemónica, buscar mostrar como la democracia queda en un segundo plano de importancia ante la lucha real por el poder político, económico y los intereses geopolíticos.
Accepted: February 8, 2021

Written by:

Mario Lagomarsino-Montoya ${ }^{17}$ https://orcid.org/0000-0001-9204-4745

Rosalba Mancinas-Chavez ${ }^{18}$ https://orcid.org/0000-0002-4218-2338

Juan Guillermo Estay-Sepúlveda ${ }^{19}$ https://orcid.org/0000-0001-7348-5529

Germán Moreno-Leiva ${ }^{20}$ https://orcid.org/0000-0001-5338-0391

Lorena Moraga Gálvez ${ }^{21}$ https://orcid.org/0000-0002-2006-3063

\begin{abstract}
The 21st Century presents a new way for the world to begin to regulate, after the violent Unipolar order that affected humanity, particularly in the nineties of the last century and in the first eight years of our current century. The United States dominated the world in the last 40 years and today, the first symptoms of its decline as an empire are beginning to be observed. The geopolitical turn, should bring an opportunity for democracy and open society, so that they can be better reflected in the diverse populations of the world. However, democracy must resist a stormy period, which marks the end of an era, in a situation of much loss of prestige that suffers as a political regime and also must, at the same time, cease to be a set of rules to start government over the market. Not easy. The objective of the article, along with glimpsing the decline of the United States as a hegemonic power, seeks to show how democracy remains in the background of importance to the real struggle for political, economic and geopolitical power.
\end{abstract}

\footnotetext{
${ }^{17}$ Investigador Universidad Adventista de Chile, Chile.

${ }^{18}$ Académica e Investigadora Universidad de Sevilla, España.

${ }^{19}$ Investigador Universidad Católica de Temuco, Chile y Universidad Adventista de Chile, Chile. Universidad de Salamanca, España.

${ }^{20}$ Académico e investigador Universidad de Las Américas, Chile.

${ }^{21}$ Académica de CFT Tecnológico de Valparaíso, Chile.
} 
Palabras Clave: Democracia, Geopolítica, Relaciones de Poder, Relaciones Internacionales, Sociedad Abierta.

\section{Introducción}

El artículo tiene su origen en la reflexión desde la ciencia política, que se ha realizado sobre las diversas situaciones que se observan a partir del declive de la potencia que ha controlado al mundo en los últimos 40 años, especialmente en el hemisferio occidental y desde la caída de la Unión Soviética como potencia unipolar, como ha sido el caso de los Estados Unidos. Son muchas las situaciones que se derivan de esta situación y que serán importantes ahora que se va configurando un nuevo mundo de carácter multipolar que vendrá a reemplazar al unipolarismo de la potencia del norte de América y que se ha visto reflejado en el último tiempo y agravado por la pandemia del COVID-19 de una actitud y aptitud que no se veía desde los inicios de la Doctrina Monroe.

El siglo XXI nos ha presentado una nueva forma en que el mundo se ha regulado, luego del violento ordenamiento unipolar que asoló a la humanidad, particularmente en la década de los noventa del siglo pasado y en los primeros años de nuestra actual centuria. Es así que, asistimos a la constitución de un nuevo mundo multipolar, al que algunos autores, como Alfredo JalifeRahme (2018) tienden a particularizar como tripolar, en el cual las potencias cabeceras serán China, Rusia y Estados Unidos. Sin perder de vista la aparición de otras potencias y lo que pueda hacer la Unión Europea. Lo claro es el declive, particularmente financiero de los Estados Unidos, pero al mismo tiempo, su no resignación a la pérdida de la hegemonía mundial. La historia demuestra que las potencias imperiales se resisten violentamente a no ser más hegemónicas. Y el momento más complejo y violento es precisamente en la caída. Hoy asistimos a un momento de transición en que nuevas superpotencias desafían a la potencia aun dominante. En este sentido, no debemos olvidar la vieja, pero muy importante "Trampa de Tucídides". Y por lo mismo, las potencias dominantes, suelen ser muy peligrosas en su caída libre. Es el momento de las agresiones propias de quien se ahoga en sus propias contradicciones. Estados Unidos pasará a ser un país gigante pero no hegemon, como adelantará Zbigniew Brzezinski, poco antes de morir. En esta pesquisa, observaremos los principales síntomas de esta situación y en particular las relaciones geopolíticas que se dan
Key Words: Democracy, Geopolitics, International Relations, Open Society, Power Relations.

en esta batalla por la supremacía mundial. De hecho, el propio Presidente Trump es un síntoma de este declive. Es uno de los Presidentes norteamericanos republicanos que no es neoliberal, sino que es un nacionalista económico. Aunque Estados Unidos aún mantiene una impresionante industria militar, el dólar y Wall Street. Para lo mismo, utilizaremos un lenguaje conceptual para sentar el concepto de geopolítica, la cual desvaloriza a la democracia y a la sociedad abierta, importándole solamente lograr cuotas de influencias en diferentes territorios, en particular en aquellos considerados como estratégicos, ya sea por su posición geográfica o por la cantidad de recursos naturales con los que cuenta un territorio. Miraremos la historia de Estados Unidos en los siglos recientes y los síntomas de su lento, pero constante declive en el mundo. Veamos lo que señala, Sergio Rodríguez en este sentido,

"La historia enseña que el proceso de decadencia y caída de los grandes imperios que han existido a través de la historia guardan ciertas similitudes independientemente de la época en la que han ocurrido, la fase del desarrollo de la humanidad en que se produjeron y los grados de avance tecnológico existentes en el momento histórico de su transcurso hacia el declive definitivo después de vivir largos períodos de auge que hacían suponer su eternidad hegemónica [...]. El problema para Estados Unidos es que esto ha comenzado a cambiar, en tanto se empieza a manifestar cierta superioridad económica, científica, tecnológica y militar de China y de Rusia, lo cual está configurando el eje principal de la conflictividad global actual. El trance generado por Estados Unidos contra la empresa china Huawei es la expresión más reciente y clarificadora de esta situación" (Rodríguez, 2019: s/p)

No obstante, lo más importante será observar el segundo plano absoluto en que queda la defensa de la democracia a nivel mundial, cuando se trata de enfrentar los escenarios que marcarán el derrotero global en busca de crecientes cuotas de predominio de estas características. La democracia queda reducida a un discurso y en 
consecuencia la libertad humana y la vida misma queda reducida a un segundo plano.

Otro crítico interesante, pero situado desde un plano cultural es Morris Berman (2003), quien plantea un ocaso cultural. Un antecedente lacónico es que solo el 12 por ciento del pueblo estadunidense tiene pasaporte. En otras palabras, 88 por ciento no tiene interés en lo que hay más allá de las fronteras de Estados Unidos. Es una sociedad muy provinciana y encerrada. No tienen una visión de ideas diferentes, de modos de vida distintos. Es sólo la ideología de Estados Unidos. Si en Estados Unidos expresas un desacuerdo crítico, inmediatamente eres un "no americano". Parece una broma, pero así es. Eso no pasa, por ejemplo, en Suecia, donde no se cataloga a los disidentes como no suecos.

Sin embargo, el cambio de ciclo geopolítico, a pesar de la muy difícil situación de la democracia hoy, debiera abrir lenta, pero continuamente una nueva oportunidad para la democracia y su intento de mayor plasmación en la comunidad. Para aquello, la democracia no deberá ser solamente aquel conjunto de reglas para dirimir elecciones, como fue la definición entregada por Norberto Bobbio (2001). Por el contrario, esta democracia que debe surgir en medio de este periodo de transición, deberá contar con dos elementos esenciales. Por un lado, intentar ser una democracia global (porque hoy enfrentamos problemas que son de carácter planetario, como el cambio climático y una pandemia, entre otros) $\mathrm{y}$, por otro, una democracia que gobierne el mercado y como consecuencia garantice derechos para sus ciudadanos. Si ello no ocurre, por mucho que Estados Unidos deje de ser el gran hegemon, la democracia estará condenada a su reemplazo por otros regímenes políticos, como ya ocurrió en el siglo XX. En consecuencia, se plasmaría lo que se denomina: "el Efecto Polanyi”. De estas temáticas, intentaremos dar cuenta en las siguientes líneas.

\section{Situación Actual. La Actual Configuración Mundial. Multipolar o Tripolar}

Escribimos desde el denominado "Hemisferio Occidental", el cual, para la actual potencia dominante -que todavía es Estados Unidos-, es parte de su política y decisiones domésticas. Y así se ha dicho con todo el desparpajo del mundo. El 1 de mayo de 2019 -en televisión- el señor John Bolton ha sentenciado sin ningún tapujo que la doctrina Monroe está de vuelta. Que no "permitirán que Rusia ponga un pie en nuestro continente americano". Así de claro, así de nítido en la cadena estadounidense FOX.
Afortunadamente para el mundo vamos ingresando muy rápidamente a una era que se ha denominado como multipolar, donde el multilateralismo jugará un rol fundamental. No obstante, esta extraordinaria buena nueva, nos encontramos en la fase final de dominio casi monopólico de Estados Unidos sobre el mundo y esta retirada y pérdida de la calidad de gendarme del planeta tiene aún elementos tremendamente dañinos y peligrosos. Todavía Estados Unidos, motu proprio es capaz de imponer sanciones a otros países, sin que las entidades multilaterales existentes puedan hacer algo material para impedirlas. Y es grotesco que no nos pidan a estas alturas de evolución histórica que creamos que a Estados Unidos le interesa la democracia, porque no es así. Y la evidencia histórica que hay para afirmar lo anterior es aplastante. Tal vez lo más cercano al cual se asemejen los cambios de régimen que provoca Estados Unidos sea el modelo libio que termino con el Gobierno del ex aliado de occidente, Muamar el Gadafi. En este punto es muy importante, presentar lo que señala el analista internacional, Atilio Boron (2016).

"Claro está que la decadencia imperial no significa, como muchos suponen, que el debilitamiento de la hegemonía estadounidense - cada vez más dominación militar y menos dirección intelectual y moral [...] - pueda ser un factor de moderación de las tendencias más agresivas y salvajes de la política norteamericana. Más bien sucede exactamente lo contrario, no tanto como producto de la idiosincrasia de ese país sino porque da cumplimiento a una regularidad sociológica que se ha verificado, sin excepción, en las crónicas de todos los imperios. Existe entre los historiadores un consenso generalizado en el sentido de que sus fases más violentas fueron aquellas en las cuales dio comienzo su descomposición [...] La decadencia del imperio norteamericano se inscribe en la misma lógica. Pese a la desaparición del temible enemigo soviético y los tan publicitados dividendos de la paz resultantes de aquel desenlace, el imperio norteamericano no ha cesado de apelar a la violencia para mantener sus posiciones en el complejo tablero de la política y la economía mundiales. Para ello ha acrecentado enormemente el gasto militar [...] aquellos directamente relacionados con el gasto de las operaciones bélicas, el armamento y su personal pero también otro tipo indirecto, tales como los gastos originados en la atención médica y psicológica del personal militar herido en las distintas misiones [...] También es preciso añadir el pago de los asesores desplegados en distintos teatros de operaciones, 
eufemismo para referirse a los mercenarios y tropa tercerizada cuyo número es cada vez mayor; los gastos de reconstrucción de la destrucción que producen las fuerzas armadas estadounidenses y cuyos mayores beneficiarios son las empresas asociadas al complejo militar industrial como Halliburton, uno de cuyos principales accionistas era el ex vicepresidente de George W. Bush, Richard Dick Cheney; y otros emolumentos también indirectamente relacionados con el gasto del Pentágono como proyectos especiales de investigación y desarrollo de nuevos tipos de armas o equipo militar. Una vez debidamente tenidos en cuenta todos estos componentes el total del gasto militar de Estados Unidos supera la supuestamente infranqueable barrera del billón de dólares, es decir, un millón de millones de dólares [...] el gasto militar de mundial del año 2015 ascendió a 1.77 billones de dólares. La asimetría militar entre Estados Unidos y el resto de los países es apabullante [...] (Boron, 2016: 13-14).

Sin duda que lo anterior, explica su decadencia económica y su condición de país quebrado y deudor, pero también explica que sus actitudes violentas y agresivas contra la comunidad internacional están lejos de desaparecer.

De la misma manera, su conducta totalitaria y apartada de los más mínimos principios universales, y mejor ni hablemos de la legalidad. La situación anterior, ha llevado a Estados Unidos a mantener conductas violentas. Así nos muestra Noam Chomsky,

"El rechazo de las obligaciones internacionales ha arraigado hasta tal punto - escribe Kaye que los gobiernos extranjeros ya no esperan que Washington ratifique los tratados ni que participe plenamente en las instituciones que aquellos crean. Pero el mundo no espera y esas leyes se hacen igualmente, aunque con muy limitada (o nula) implicación estadounidense. Aunque nada tiene de nuevo, esta práctica se ha ido afianzando más si cabe en años recientes, unida a una aceptación callada dentro del propio país de la doctrina según la cual Estados Unidos tiene todo el derecho del mundo a actuar como un Estado canalla. Por poner un ejemplo típico de ello, recordemos que hace apenas unas semanas, fuerzas de operaciones especiales estadounidenses raptaron a un sospechoso Abu Anas al-Libi - de las calles de la capital de Libia, Trípoli, y lo trasladaron a un navío militar para interrogarlo sin la presencia de un abogado y sin que se garantizaran sus derechos como detenido. El secretario de Estado John Kerry informó a la prensa que aquellas acciones eran legales porque se ajustaban a la ley estadounidense y nadie puso ninguna objeción en particular a semejante argumento. Pero los principios solo tienen validez sin son universales" (Chomsky, 2017: 173-174).

Sin embargo, es evidente el detrimento de poder por parte del hegemon. Ya los golpes de Estado no son tan simples como antes. $\mathrm{Y}$ no es el mismo contexto, de cuando Estados Unidos hacía y deshacía a su antojo. Hoy tiene que mentir mucho más y eso quedó demostrado por ejemplo, en la invasión a Irak bajo el pretexto de "armas de destrucción masiva". Y cuando se miente tanto las cosas se complican. Recordamos antaño las invasiones, y las experiencias de Granada y de la Isla Diego García, como ejemplos periféricos de lo que ha sido la horrible historia de los Estados Unidos en esta materia. A pesar de lo anterior, se busca por todos lados imponer la voluntad imperial y para ello cuenta con otro tipo de aliados de este tiempo. Entre otros, la casi totalidad de los medios de comunicación y en particular las cadenas de televisión que dicen prácticamente todas lo mismo. Mientras y en paralelo, se busca satanizar a lo diferente, a través de los medios de comunicación unidimensionales, ya sea un individuo o algún gobierno, hasta convertirles, a los ojos de las opiniones públicas de este tiempo, en la mismísima manifestación del mal sobre la tierra. ¿Qué otra cosa es aquello que indigentemente el Presidente George W. Bush denominó como "Eje del Mal?". Las guerras preventivas son otra invención para agredir a quien se defina unilateralmente como el enemigo de turno. Veamos lo que señala, Tzvetan Todorov al respecto, "La guerra preventiva, tanto si responde a un ataque real como a una mera impresión de inseguridad, se apoya en una apreciación obligatoriamente parcial y subjetiva. El ejemplo de Estados Unidos podría volverse contagioso: si aceptamos que cada país ataque a los demás apoyándose tan solo en sus impresiones, abrimos la vía para una guerra permanente de todos contra todos" (Todorov, 2004: 57). En una suerte de regreso al estado salvaje descrito por Thomas Hobbes, la guerra preventiva fue otra bestialidad generada por la política exterior de los Estados Unidos que logró forjar un mundo aún más violento. Pero logró algo más. Logro crear resentimiento. A pesar de aquello, que no es menor, avanzamos hacia una situación multipolar con la aparición y reaparición en algunos casos de grandes potencias, que se preparan para superar a los Estados Unidos como ente hegemónico del mundo. No es que 
China y Rusia vayan a reemplazar a Estados Unidos en su posición de policía del mundo. No. Solamente como agrupación de países, tendrán una preponderancia en la economía y en la capacidad militar que se equiparará y luego superará al país que hoy todavía mantiene un ejército planetario. Baste con recordar las proyecciones económicas que ha realizado la OCDE para 2030. En el 2030, Estados Unidos será el $18 \%$ del PIB mundial, mientras que China será el $27 \%$ e India el $11 \%$ del PIB mundial respectivamente, sin embargo, estas proyecciones son antes de la pandemia y las nuevas del Banco Mundial ven un retroceso que no se apreciaba desde la segunda mitad del siglo XIX. Todavía no hablamos de Rusia, que es un país gigante territorialmente, que posee un enorme arsenal nuclear y que tiene una serie de riquezas en hidrocarburos, es decir, Rusia tiene todas las condiciones de superpotencia para jugar nuevamente en estas ligas. El Presidente Trump es un líder de lo inmediato, del triunfo corto y del más breve plazo, es el Presidente del Twitter, mientras que el Presidente de Rusia Vladímir Putin es el político más cerebral del mundo y el líder chino Xi Jinping, juega en el largo plazo. No tiene tiempos, ni elecciones. Todos los condimentos para el fin de la premura norteamericana.

Así las cosas, como veremos en otra parte, el mundo multipolar se ausculta en un escenario al menos tripolar, con tres centros de poder muy definidos: China, Rusia y los Estados Unidos. Por una parte, la ruta de la seda (que en realidad son tres) y el órgano de cooperación de Shanghái. Todo un nuevo mundo que se comienza a dibujar, frente a la desesperada caída de los Estados Unidos. Esa práctica finalmente le ha llevado a que ese país se encuentre quebrado financieramente y que al mismo tiempo su economía se base justamente en la industria militar que requiere de guerras para rentar. Pero esto último comienza a llegar a su fin.

\section{La geopolítica está de Vuelta. Así se conducen las Relaciones Internacionales}

La geopolítica está de vuelta. Tal vez nunca se ha ido. A pesar de ser una geopolítica distinta de la guerra fría. Una geopolítica que tiene más de dos actores como lo fueron Estados Unidos y la Unión Soviética, en el periodo Post Segunda Guerra Mundial. Sin embargo, la apreciación de los actuales conflictos lo son también por situaciones de poder y de dominación esta vez en esta geopolítica de dominio de la tecnología. Aunque se mantiene como muy importante la aspiración sobre el dominio de los recursos naturales como sostén de la cuarta y quinta revolución industrial. Como hemos sostenido, en este marco la lucha por la democracia y la libertad de los seres humanos pasa a un segundo plano.

Lo que podemos apreciar a simple vista es que lo importante son las ubicaciones estratégicas de los países y los recursos que poseen. Luego su crecimiento económico, su capacidad de incidir en otras regiones y su poder militar. Podemos así apreciar lo que indica Pascal Bruckner, "En cuanto a las grandes compañías, apenas se preocupan de los derechos humanos y se permiten explotar sin escrúpulos a mujeres y niños, comerciar con regímenes autoritarios o totalitarios. (Ejemplo, la empresa petrolífera de Estados Unidos UNOCAL tuvo tratos con los talibanes, favorables al paso por su territorio de los oleoductos procedentes de Asia Central). Creer como Milton Friedman, que el mercado armoniza los intereses individuales por medio de una especie de acuerdo espontáneo y que por eso la indiferencia mutua y el repliegue sobre uno mismo constituyen los mejores garantes de la paz [...]" (Bruckner, 2003: 163).

Lo anterior, se da en particular en los países con visión geoestratégica y aspiraciones globales. En este sentido, el propio Brzezinski hablando de cómo se ha plasmado el poder de los Estados Unidos, sostiene:

“el colapso de su rival (URSS) dejó a los Estados Unidos en una posición única: se convirtieron, simultáneamente, en la primera y única potencia realmente global. Y, sin embargo, la supremacía global de los Estados Unidos recuerda, en cierto modo, a la de los viejos imperios, a pesar de que el campo de acción regional de éstos era más restringido. Esos imperios basaban su poder en una jerarquía de vasallos, tributarios, protectorados y colonias y solían considerar como bárbaros a quienes se encontraban en el exterior. En alguna medida, esa terminología anacrónica no resulta totalmente inapropiada para algunos de los Estados que actualmente se mueven en la órbita estadounidense. Igual que en el pasado, el ejercicio del poder imperial estadounidense se deriva en gran medida de la organización superior, de la habilidad para movilizar con rapidez vastos recursos económicos y tecnológicos con propósitos militares, del vago pero significativo atractivo cultural del American way of life y del franco dinamismo y la inherente competitividad de las élites sociales y políticas estadounidenses" (Brzezinski 2016: 19). 
El dominio de los Estados Unidos en gran parte del mundo tuvo evidentemente una aspiración geopolítica. La democracia y la sociedad abierta fueron el subterfugio para invadir y someter a cuanto país pudiera oponerse a esos afanes imperiales. Y todavía en fase de agonía imperial es así. La supremacía estadounidense en los diferentes continentes y subcontinentes del mundo se caracterizaron por la violencia y la inestabilidad producida por la superpotencia. Esa inestabilidad que Brzezinski denominó como táctica o caos constructivo. Así Germán Gorráiz señala,

"la Doctrina Carter inspirada por Brzezinski (1980), tenía como objetivo la implementación en Oriente Próximo y Medio del llamado "caos constructivo", concepto que se basaría en la máxima atribuida al emperador romano Julio César "divide et impera", para lograr la instauración de un campo de inestabilidad y violencia en la zona (balcanización) y originar un caos que se extendería desde Líbano, Palestina y Siria a Iraq y desde Irán y Afganistán hasta Pakistán y Anatolia (Asia Menor)" (Gorráiz, 2017: s/p).

Esta fórmula implica dividiendo los países en sectores, atomizando las naciones y fomentando guerras entre esas diversas facciones. Esa fue la fórmula en la que se asentó el dominio estadounidense por el mundo. Lo anterior y en particular en Latinoamericana acompañada de Golpes de Estado, para instalar dictaduras que favorecieran y cuidaran los intereses del país del norte, en aquello que denomina como: "su patio trasero".

Ahora en el declive estadounidense, y en el camino hacia un nuevo orden del mundo, esas prácticas de Estados Unidos tendrán que ir extinguiéndose de la faz de la tierra como una de las estrategias más nocivas que haya conocido la historia de la humanidad. Debiéramos en los próximos años ingresar a un mundo de mayor colaboración y respeto por las autonomías de los diferentes pueblos, respetando sus formas de gobierno que esos mismos pueblos se han dado. En este sentido, se observa que las nuevas superpotencias como China y Rusia, más allá de sus intereses geoestratégicos, por lo menos mantienen compostura ante los países pequeños con los cuales mantienen relaciones, especialmente comerciales. Hará falta un trabajo en favor de la democracia. No todo puede ser comercio y hegemonía. Se necesita potenciar sistemas políticos que pongan al ser humano como el real centro de interés del mismo sistema y no como su esclavo.

No obstante, para que quede claro el giro geopolítico, debemos hablar de esta disciplina de forma aplicada, donde se muestra claramente, como ya Estados Unidos, no tiene sus antiguas capacidades para dar vuelta a las cosas en correspondencia con sus intereses.

Crisis en la Democracia y la Sociedad Abierta. No pueden con la fuerza de la Geopolítica

La geopolítica es muy fuerte. Y particularmente fuerte y con capacidad dominadora es la geopolítica de carácter imperial, como la que ha practicado Estado Unidos en los últimos 75 años. Las relaciones centro-periferia, son las peores que pueden existir, para los territorios justamente considerados como periféricos. Pues son vistos por el centro como colonias que deben obedecer las órdenes, dictámenes e imposiciones venidas desde la metrópolis. Las democracias han convivido con esta situación en nuestro tiempo y de la cual no se han podido zafar, puesto que sus respectivos Estados tienen que sobrevivir y para ello actúan como periferia en una geopolítica cercana al esclavismo. Y en las relaciones económicas esta situación ha sido simplemente brutal. Así Immanuel Wallerstein, señala,

"La división axial del trabajo en una economía - mundo capitalista divide a la producción en productos centrales y en productos periféricos. El concepto centro - periferia es relacional. Lo que queremos decir por centro - periferia es el grado de ganancia del proceso de producción. Puesto que la ganancia está directamente relacionada con el grado de monopolización, lo que esencialmente significamos por procesos de producción centrales son aquellos controlados por cuasimonopolios. Los procesos periféricos son entonces los verdaderamente competitivos. Cuando ocurre el intercambio, los productos competitivos están en una posición más débil y los cuasimonopólicos en una posición más fuerte. En consecuencia, hay un flujo constante de plusvalía de los productores de productos periféricos hacia los productores de productos centrales. Esto es lo que se ha denominado intercambio desigual" (Wallerstein, 2005: 46).

Esta situación llevada a las áreas sociales y políticas plantea simplemente una relación de dependencia con el centro. 
Lo preocupante de la situación en la que estamos, es que todos los elementos se concentran en relaciones de poder y de incidencia. No obstante, al parecer a nadie le interesa la salud de la democracia y de la sociedad abierta. La historia de finales del siglo XX y de lo que va del siglo XXI no es la historia de la lucha por la democracia a nivel global. Es la historia más bien de la incidencia de la economía, bajo la ideología neoliberal. De esta forma, Rüdiger Safranski, señala," El globalismo neoliberal es una ideología legítimamente del movimiento sin trabas del capital en su búsqueda de condiciones favorables a la rentabilidad. Trabaja con la advertencia de que podemos vernos separados de las corrientes de capital. Con tales palabras pone sobre nuestras cabezas un escenario amenazador, y la amenaza no persigue otro fin que la imposición del primado de la economía. El estado y la cultura han de servir a la economía." (Safranski, 2005: 21-22). Y por supuesto la democracia y la sociedad abierta deben estar al servicio de la economía, en una relación de dependencia y si se quiere de usurpación de valores. Todo a disposición de los grandes negocios globales. Una de las luchas de hoy no es la democracia. Una lucha geopolítica de hoy es quién controlará el $5 \mathrm{G}$ y con ellos gran parte de la información sobre los asuntos globales. La gira del Señor Pompeo por Sudamérica ha tenido este sello sin lugar a dudas. Y la democracia ha pasado a ser un discurso vacío, sin contenido, absolutamente subordinado a los parámetros del mercado y a los intereses geopolíticos de las potencias que se disputan la primacía mundial en los próximos años. La lucha por la supremacía, que se expresa en las controversias por los mercados protegidos, en las barreras arancelarias, en el proteccionismo y las sanciones económicas deja de lado, todo lo sublime que es la preocupación por tener sociedades en las cuales los seres humanos sean cada vez más libres y no unos simples peones de las grandes jugadas de ajedrez geopolíticas del mundo. Estamos en el marco de un escenario con complicaciones extras. Pues, somos testigos presenciales, como lo fue Tucídides desde su exilio, de la caída de una de las superpotencias de la historia que ha tenido dominio y control global, de forma prácticamente unilateral. Un control planetario, que también se expresó en la zona más poblada del mundo, sobre la cual había advertido Mackinder que quien dominara ese territorio dominaría el globo completo. Pues se trata del territorio más poblado del mundo que indudablemente convierte a América y a Oceanía periféricos con respecto al centro del mundo. En su famosa hipótesis geopolítica del pivote. Nos referimos al continente euroasiático. Estados Unidos fue la primera potencia no euroasiática, que determinó los destinos de ese territorio donde habita la mayor parte del planeta.

Ahora bien, en nuestro momento espaciotemporal y frente al colapso de los Estados Unidos que representa una oportunidad en pos de ir tras los ideales blandos en el mundo. Al parecer fuera un muy buen momento para la democracia. Pero la situación táctica es bastante distante de este anhelo. Como hemos sostenido a lo largo de este texto, toda la evidencia que existe muestra que los imperios en su fase terminal muestran su peor cara y los elementos de agresión, tribales y salvajes se manifiestan con la mayor fuerza. Esta situación, se puede reflejar en ese afiche de campaña que utilizó el entonces candidato Donald Trump, i"Make America Great Again!' y en donde se le podía apreciar en la ciudad de Detroit, la ciudad símbolo del periodo de mayor esplendor de la industria automotriz. Una suerte de ciudad fantasma. Sale Trump frente a la fábrica vacía, sin operarios cayéndose a pedazos, los automóviles americanos no pudieron competir con los japoneses, luego con los coreanos y ahora mejor no hablemos de los chinos. A Trump no le alcanzará para make america great again. En este sentido, el destacado matemático y prospectivista noruego, que anticipó el derrumbe de la Unión Soviética en base a modelamientos matemáticos prospectivos, Johan Galtung (2017), ha sostenido que el fin del imperio americano se dará entre los años 2020 y 2025.

En consecuencia, los problemas que esta situación temporal traen a nuestras ya agónicas democracias son de un muy mal pronóstico. Habrá que atravesar un desierto caliente, hasta lograr ver el horizonte. Lo anterior, en medio de otras convulsiones como lo es el predominio de la aciaga versión de la economía, denominada como neoliberalismo, que ha sido una fábrica de multiplicación de la pobreza y que la democracia tiene que controlar. Es un periodo excepcional, puesto que plantea una dialéctica de una tremenda y multidimensional matriz para su intento de solución. Lo claro y en donde no nos podemos perder, es el hecho de que el imperio más grande de todos los tiempos tiene fecha de vencimiento y que esa situación debe ser una oportunidad para la humanidad, para mejorar nuestra estadía en este planeta, en todos los sentidos posibles. 
Sin embargo, la democracia del cibermundo y de la ciberpolítica, tiene que escuchar lo que nos dice, Jaron Lanier,

"En los círculos que defienden la ciberdemocracia, es un dogma de fe que hacer la información más libre, en el sentido de más copiable, también conducirá al mundo más democrático y abierto posible. Sospecho que no es así, y ya he señalado algunos de los problemas. Un mundo abierto en la superficie se vuelve más cerrado a un nivel más profundo. No podemos saber las correlaciones que Google, Facebook, una compañía aseguradora o una entidad financiera han establecido a partir de nuestros datos, y ese es el tipo de datos que mayor influencia tienen sobre nuestra vida en un mundo en red" (Lanier, 2014: 257-258).

\section{Aprovechando el Cambio de Ciclo Geopolítico en favor de la Democracia y de la Sociedad Abierta}

Este momento de transición geopolítica debiera ser la oportunidad de fortalecer el régimen democrático, de hacer y mostrar que tiene relación con la vida de las personas y que no es solamente un procedimiento para elegir autoridades cada cierto tiempo. La democracia es la que tiene que regir los mercados y no al revés. El mercado por sí sólo no puede garantizar las libertades de las personas. Al contrario, es la democracia y la política la que garantiza lo anterior. Sin embargo, la salud de la democracia en la actualidad no es buena. En América se observa lo que señala el analista internacional, José Rodríguez Elizondo, "La dificultad mayor estriba en que el contexto occidental dejó de ser estimulante. Los Estados Unidos [...] no asumen la misión de expandir la democracia, ni siquiera de manera tutelar. El gobierno de Donald Trump ha dejado fuera de juego la vieja doctrina del "destino manifiesto". Está pasando del paternalismo del "buen vecino" (Franklin, D. Roosevelt) y del apoyo de la Alianza para el Progreso (J. F. Kennedy), al aislamiento, la apología del Muro divisorio y hasta a las groserías contra países de la región" (Rodríguez, 2018: s/p). A manera de hipótesis, con bastante posibilidad de ser verificada, podemos sostener que sencillamente Estados Unidos nunca ha promocionado la democracia. Lo que ha promocionado han sido sus propios intereses nacionales extendidos hacia el resto del mundo. Por lo mismo, su momento de declive es un espacio para reimpulsar la democracia, en medio de la nueva geopolítica. El fin del dominio del último hegemon significa la posibilidad de pensar una democracia más global, en donde se vaya generando un ambiente planetario en redibujar esta forma de gobierno. Tenemos que trabajar grandes temas que tienen que ver con nuestra civilización. Para eso necesitamos pensar globalmente. Sin la presencia decisiva de Estados Unidos, podremos tratar como especie temas tan importantes como el cambio climático, el poblamiento del planeta, los refugiados $y$ desplazados, el futuro del trabajo, las pensiones, la sanidad, la educación y todos los temas de los cuales se tiene que hacer cargo la democracia.

Antes de que se termine de acabar el modelo de globalización que inventó Estados Unidos, estaría muy bien Globalizar la democracia y hacer de la ONU un ente más potente y respetado, aprovechando que ya no estará en su esplendor uno de los países que se especializó en ¿incluir? sus acuerdos.

En consecuencia, la democracia tendrá que salir del atolladero en el que se encuentra para preocuparse de los temas realmente importantes. La era post Estados Unidos se debe aprovechar para intentar democratizar el mundo cada vez. Dejar de lado la violencia y la intromisión en los asuntos de los pueblos para avanzar en el perfeccionamiento del sistema democrático tan desprestigiado en este tiempo.

Y la democracia para revivir y revitalizarse tiene que tomar la decisión de Gobernar al mercado. El cambio de ciclo geopolítico, también hay que aprovecharlo de esta forma. Ha sido una de las más grandes mentiras de todos los tiempos que el mercado se autorregula. Ni siquiera ha sido mercado y menos libre. Veamos que nos dice el famoso economista y teórico social, Franz Hinkelammert,

"El mercado no es un sistema autorregulado. Las así llamadas fuerzas de autorregulación del mercado no existen; lo que hay es una determinada autorregulación de mercados particulares, no del mercado en su conjunto, el cual no tiene la más mínima tendencia al equilibrio, tiende siempre de nuevo y sistemáticamente a desequilibrios. El mercado es pura voluntad del poder. Las mencionadas amenazas globales concretas son desequilibrios del mercado. A favor de ciertos equilibrios financieros, éstas son sistemáticamente aumentadas. La política del crecimiento económico muestra todavía otro lado: cuanto más se insiste en una ciega política de crecimiento, tanto más son aumentadas las amenazas globales y, como consecuencia, se sacrifica cualquier política que intenta 
afrontarlas. Ésa es la lógica de la estrategia de globalización" (Hinkelammert, 2018: 181-182).

Probablemente en este cambio de giro que ha comenzado a producirse antes del primer cuarto del siglo XXI, la democracia se juega mucho de su capital como sistema político. De alguna manera el predominio estadounidense siempre fue distante de la idea de democracia y nunca se dio el tiempo de potenciarla. En esta etapa, la democracia tiene que dejar de ser un conjunto de reglas para comenzar a ganarse la defensa a muerte por parte de las grandes masas de poblaciones. Una de las tareas es ser más cercana. Pero la primera es el dominio y gobierno del mercado. Si la democracia no gobierna el mercado, la sociedad reaccionará por uno o por otro lado. Es de recordar lo planteado por Karl Polanyi en 1944 (2017). No es prudente que el mercado se imponga sobre la sociedad y política. Es al revés, de lo contrario habrá reacción, como fue el fascismo y el socialismo en momentos diferentes. Este es un tema que entendieron economistas como John M. Keynes, pero que los economistas neoliberales, muy en la lógica estadounidense y de la teoría monetaria, han dejado de lado. Un tanto el declive, particularmente financiero de los Estados Unidos, viene por este lado. Por eso dijimos que el propio Presidente Trump es una reacción a esta situación.

Si el nuevo mundo multipolar, que implica una nueva distribución del poder, permite que florezcan las más diversas expresiones de democracia, se habrá dado un gran paso adelante y probablemente la sociedad recuperará su facultad de dirigir, entre otras cosas la economía y no quedar presa de las decisiones autónomas de ésta que han llevado al mundo al abismo una y otra vez en el siglo XX y en lo que va del siglo XXI (Stiglitz, 2002).

\section{Conclusiones}

1. El declive estadounidense es por el momento una bajada financiera, como consecuencia de soportar el presupuesto y gasto militar más grande de todo el planeta y las acciones que esta situación ha conllevado. Sin embargo, se trata de una bajada sostenida y con ínfimas posibilidades de romper la tendencia.

2. La geopolítica estadounidense fue la propia de un imperio con un centro y una periferia y el sometimiento de esta última a los designios y caprichos de la metrópolis.

3. La democracia y la sociedad abierta fueron un argumento discursivo, para llevar adelante todas las intervenciones que aseguraran el poder de Estados Unidos, en las diferentes regiones del mundo.

4. Esta situación se encuentra hoy en el comienzo de su fin. Y se ausculta un mundo más horizontal con nuevas potencias más respetuosas de los órdenes políticos que se den los diferentes países en el concierto mundial.

5. La democracia, en este contexto tiene una oportunidad, en base a dos argumentos. Por un lado, que asuma los problemas globales, con pensamiento y dimensión global y por otro, que entre de lleno a gobernar el mercado.

6. La nueva democracia, en el giro geopolítico tratado, deberá garantizar derechos y materialidad a los individuos, de lo contrario será reemplazada por otros regímenes políticos alternativos.

\section{Referencias}

Berman, M. (1992). Cuerpo y Espíritu. La Historia Oculta de Occidente. Santiago: Editorial Los Cuatro Vientos.

Bobbio, N. (2001). El Futuro de la Democracia. México: Editorial Fondo de Cultura Económica.

Boron, A. (2016). América Latina en la Geopolítica del Imperialismo. Valparaíso: Editorial América en Movimiento.

Brzezinski, Z. (2016). El Gran Tablero Mundial. La Supremacía estadounidense y sus imperativos geoestratégicos. Editorial Paidós. Bruckner, P. (2003). Miseria de la Prosperidad. La Religión del Mercado y sus Enemigos. Barcelona: Editorial Ensayo TUS QUEST.

Chomsky, N. (2017). Porque lo Decimos Nosotros. Ideal Democrático, estrategias de poder y manipulación en el siglo XXI. Barcelona: Editorial Paidós.

Galtung, J. (2017) "Colapso de Estado Unidos en 2020", Alfredo Jalife - Rahme. TELESUR, Agosto 2017. https://www.telesurtv.net/bloggers/Colapso-deEU-en-2020-Johan-Galtung-20170830-

0005.html

Gorráiz, G. (2017). "EEUU y el Nuevo Orden Mundial de Brzezinski”. Liberty and Knowledge, abril 2017. http://www.libertyk.com

Hinkelammert, F. (2018). Totalitarismo de Mercado. El mercado capitalista como ser supremo. México: Editorial Akal.

Jalife-Rahme, A. (2018). El (Des)Orden global en la era "Post Estados Unidos". México: Grupo Editorial Orfila.

Lanier, J. (2014). ¿Quién Controla el Futuro? Barcelona: Editorial DEBATE. 
Polanyi, K. (2017). La Gran Transformación. Los Orígenes Políticos y Económicos de Nuestro tiempo. México: Editorial Fondo de Cultura Económica.

Rodríguez Elizondo J. (2018). Democracia en Ámerica Latina. Estado de Situación y Prospectiva. Santiago: Cono Sur.

Rodríguez Gelfenstein, S. (2019). "El Inevitable Declive Estratégico de Estados Unidos”. Sputnik, marzo 2019.
Safranski, R. (2005) ¿Cuánta Globalización Podemos Soportar? Buenos Aires: Editorial TUS QUESTS.

Stiglitz, J. (2002). El Malestar en la Globalización. Buenos Aires: Editorial Taurus. Todorov, T. (2004). El Nuevo Desorden Mundial. Reflexiones de un europeo. Barcelona: Editorial Península, Barcelona.

Wallerstein, I. (2005). Análisis de Sistemas Mundo. Una Introducción. México: Editorial Siglo XXI. 